\title{
Relações políticas internacionais: como entendê-las?
}

\author{
Maria Izabel Mallmann*
}

\section{Introdução}

Embora as relações internacionais tenham existido desde o surgimento das primeiras unidades políticas, a disciplina dedicada exclusivamente a seu estudo é bastante recente, tendo se firmado, enquanto tal, na segunda metade do século XX.

A História, o Direito e a Filosofia têm sido, desde épocas pretéritas, as disciplinas que, cada uma dentro de sua especificidade, mais contribuíram para o conhecimento e compreensão das relações internacionais. O registro e sistematização da história diplomática foram, durante muito tempo, um dos mais importantes mecanismos de estudo dessa dimensão da realidade sociopolítica. Da mesma forma, a normatização das relações entre atores soberanos em cenários crescentemente complexos, além do necessário conhecimento e compatibilização dos diferentes processos e estruturas jurídicas nacionais

* Doutora em Ciência Política pela Sorbonne Nouvelle Paris III (França) e professora do Departamento de Ciências Sociais da Pucrs. Organizadora e autora na coletânea Paz e guerra em tempos de desordem. Porto Alegre: Edipucrs, 2003. E-mail: mismall@pucrs.br.

\begin{tabular}{|l|l|l|l|l|l|} 
Civitas & Porto Alegre & v. 5 & n. 2 & jul.-dez. 2005 & p. 233-244 \\
\hline
\end{tabular}


consolidou uma área do conhecimento específica do Direito. As reflexões político-filosóficas, a respeito do advento das instituições modernas, legaram importantíssimas contribuições para a análise das relações internacionais. Assim, o aporte dessas disciplinas mantém-se imprescindível para a compreensão do fenômeno nos dias de hoje.

As Ciências Sociais, consolidadas mais tardiamente, valem-se em grande medida dos conhecimentos aí gerados. O conhecimento jurídico sobre a ordem instituída e suas estruturas; as contribuições da História para a reconstituição dos processos e da Filosofia para a reflexão sobre a natureza humana e de suas instituições, são basilares para a análise política e sociológica em qualquer domínio e, particularmente, no das Relações Internacionais. As Ciências Naturais que estiveram presentes no surgimento da Sociologia, fundamentando a teoria sociológica funcionalista, também contribuíram, na segunda metade do século XIX, juntamente com a Matemática e a Psicologia para o desenvolvimento de métodos de análise do social, e foram largamente utilizados nas análises sociológicas das Relações Internacionais.

As Relações Internacionais, propriamente ditas, reivindicam, em anos recentes, o status de disciplina autônoma, o que implica em identificar objeto e método próprios. Mesmo reconhecendo a premência de eleger critérios para o recorte do que caracteriza o internacional, é incontornável reconhecer que essa área mantém-se tributária do conhecimento gerado e das metodologias desenvolvidas pelas disciplinas tradicionais. A complexidade das Relações Internacionais contemporâneas chama a si os recursos analíticos de todas as disciplinas as quais concernem as relações humanas e sociais internacionalizadas. Pode-se dizer, assim, que, antes mesmo de ser consolidada, a disciplina cede lugar à área de Relações Internacionais, essencialmente interdisciplinar.

As abordagens das Relações Internacionais realizadas a partir do enfoque das Ciências Sociais buscam no conhecimento produzido pelas disciplinas tradicionais, os elementos imprescindíveis para a realização de suas análises, cuja ênfase recai sobre processos de conflito e cooperação, responsáveis tanto pela organização política e social das sociedades quanto por sua superação.

Neste trabalho, busca-se caracterizar as duas principais matrizes teóricas que balizam as análises sobre política internacional, mostrando sua filiação ao pensamento político e filosófico clássico. 


\section{Especificidade das Relações Internacionais}

Grandes teóricos do século XX dedicaram parte de seus estudos a precisar as características da área de Relações Internacionais. Pelo menos dois deles, Hans Morgenthau e Raymond Aron, fizeram escola. São comumente identificados à escola Realista, embora haja diferenças importantes em seus estudos. Morgenthau (1990, p. 131-147) procurou desenvolver uma teoria da política, interna e internacional, identificando na busca do poder a essência da relação política. Aron (1990, p. 148-152) dedicou-se a identificar a especificidade das Relações Internacionais e encontrou em Max Weber uma contribuição fundamental, qual seja, a de identificar no Estado o monopólio do uso legítimo da força. Diferentemente de Morgenthau, para quem é possível uma teoria geral derivada da observação das escolhas racionais dos dirigentes, Aron renega as generalizações e preconiza uma cuidadosa reconstituição histórica e atenção sociológica.

No mundo marcadamente estatocêntrico de meados do século XX, Raymond Aron identificou a especificidade das Relações Internacionais verificando: "( o que $)$ diferencia as relações entre comunidades politicamente organizadas de todas as outras relações sociais" (Aron, 1990, p. 148). E essa diferença, segundo o autor, seria o fato de, nas relações entre comunidades politicamente organizadas, o uso da violência ser admitido como norma legal e legítima. Apesar da utilidade desse critério num cenário dominado por atores estatais, nos dias atuais, em que a diversidade de atores torna mais complexo o meio internacional, esse enfoque restringe acentuadamente o escopo das Relações Internacionais. Ficariam fora de sua área de estudo todas as relações entre atores não estatais, uma vez que não usufruem da prerrogativa do uso legal e legítimo da força na defesa de seus interesses.

Considerando as dimensões dos fenômenos de internacionalização e de globalização perceptíveis a partir das últimas décadas do século XX, pode-se dizer que passam a ser próprios da área de estudo das Relações Internacionais os fenômenos de alcance e impacto mundiais que, diferentemente do que foi originalmente característico de tais relações, envolvem outros atores além dos Estados nacionais.

Nesse sentido, seria mais útil o conceito desenvolvido por Morgenthau, que identificou nas relações de poder o traço característico das Relações 
Internacionais. Ou seja, identificou-as como sendo um fenômeno político, passível de existir sob diversas formas institucionais. É certo que esse traço é característico das relações políticas em geral, não sendo específico das Relações Internacionais, como bem salientou Aron. Porém, é inegável que a contribuição de Morgenthau é mais útil para a análise das relações internacionais de nossos dias do que a de Aron, na medida em que as relações políticas e sociais atuais extrapolam crescentemente os limites das coletividades politicamente organizadas, instituindo dimensões relacionais mais amplas, cujos formatos ainda são imprecisos.

\section{Teorias das Relações Internacionais}

Para facilitar a apreensão das matrizes teóricas sobre Relações Internacionais, as teorias têm sido agrupadas em categorias criadas a partir de critérios variados, escopo explicativo, método, atores privilegiados, entre outros, conforme cada autor. Embora se saiba que todo sistema classificatório é essencialmente simplificador, por negligenciar as especificidades responsáveis pela originalidade e riqueza de cada pensamento, recorre-se sistematicamente a ele, como recurso que facilita o mapeamento das teorias, mas não dispensa o estudo pormenorizado das mesmas.

Dentre os inúmeros esforços classificatórios, destaca-se o formulado por Philippe Braillard (1990) que institui duas categorias básicas: Teorias Gerais e Teorias Parciais, a partir do escopo explicativo das mesmas. As primeiras agrupam as contribuições de teóricos que, a partir de uma visão global, se preocuparam em esclarecer as relações internacionais em seu conjunto. Este é o caso, segundo Braillard, de três teorias, a realista de Hans Morgenthau, a diplomático-estratégica de Raymond Aron e a marxista-leninista. As Teorias Parciais reúnem aquelas teorias que se propõem a aprofundar o conhecimento de aspectos das relações internacionais, como é o caso das teorias da integração ou das organizações internacionais, por exemplo. Isso não quer dizer que as Teorias Parciais neguem o objeto das Teorias Gerais. De fato, nenhuma teoria prescinde, implícita ou explicitamente, de uma compreensão de mundo que dê sentido aos fenômenos, internacionais ou não, e que permita interpretá-los diacronicamente. A relevância das Teorias Gerais reside precisamente no fato de se preocuparem com a compreensão global da realidade e de buscarem produzir sentido para a ação humana e social. 
A ordem estatocêntrica moderna tem estado fundamentada em pressupostos político-filosóficos dos séculos XVI, XVII e XVIII que se mantêm vigentes nas análises das Relações Internacionais contemporâneas.

\section{A teoria do Estado de Natureza}

A teoria do estado de natureza, desenvolvida por Thomas Hobbes, no século XVII, tem estado, implícita ou explicitamente, presente nas teorias gerais das Relações Internacionais. Segundo esse pensador, os homens, na ausência de um poder que os constranja, vivem em estado de natureza, ou seja, em permanente luta uns contra os outros. A necessidade de alguma estabilidade e de preservação da vida leva os homens a firmar um pacto, através do qual cada um aliena sua liberdade individual em benefício de uma instância superior garantidora da convivência pacífica entre todos, já que eles, isoladamente ou em grupo, são incapazes de garanti-la. Os indivíduos legitimam, assim, o Estado, com poder soberano e inalienável sobre a sociedade. Fundamentada em uma concepção negativa e pessimista da natureza humana, segundo a qual os homens não superam jamais sua condição egoísta e belicosa, essa teoria defende a perpetuação do Estado como único modo de coibir a reinstalação da anarquia e do caos. Anarquia, aliás, que perdura entre os Estados, uma vez que, entre eles, não é firmado um pacto instituinte de uma ordem supranacional.

Essa versão do pacto social institui esferas distintas de relações políticas, uma regrada pela lei, interna aos Estados nacionais, e outra, externa, afeita às relações anárquicas e conflituosas entre eles. Os indivíduos, temerosos uns dos outros, não ousam reivindicar autonomia ao Estado, guardião absoluto da ordem. Em conseqüência disso, os Estados perpetuam-se como unidades básicas do sistema internacional em permanente estado de guerra uns contra os outros, uma vez que, à semelhança dos indivíduos em estado de natureza, constituem-se em ameaças mútuas constantes. Essa é, portanto, uma leitura essencialmente pessimista das relações internacionais que não contempla a possibilidade de ocorrer entendimento duradouro entre os Estados e, segundo a qual, a paz decorre necessariamente do equilíbrio de poder entre eles, em que a ameaça mútua é o instrumento principal. Por reivindicar uma leitura da realidade fiel aos fatos, a escola de pensamento derivada dessa vertente teórica é denominada realista. 
Outra interpretação da ordem internacional, antropologicamente mais otimista, fundamenta-se na versão kantiana do estado de natureza e na versão lockeana do contrato social. Nessa perspectiva, moral e política são indissociáveis podendo a vontade humana, moralmente sustentada e racionalmente orientada, conduzir a ação humana na construção de uma sociedade pacífica e libertária em que o progresso material e a realização individual sejam possíveis. De acordo com a matriz contratualista liberal, é desejável e possível que as restrições que asseguram alguma estabilidade à política interna sejam expandidas ao âmbito internacional somando previsibilidade ao sistema, mediante adesão a tratados e instituições internacionais. Nesses termos, seria possível assegurar a paz por outras vias que não fossem os instáveis meios do equilíbrio de poder. Dessa perspectiva, o Estado é instrumental aos interesses dos indivíduos que, tendo-os contrariados, podem readequar a organização política. Dependendo da ênfase que se dê, pode-se identificar nessa vertente teórica uma forte dimensão idealista no sentido de que, sob influência kantiana, confia no poder do homem para conduzir a história ou, também, se pode identificar uma importante influência contratualista liberal, de inspiração lockeana, na medida em que admite o controle dos indivíduos sobre o Estado. Por isso, a escola dela derivada pode tanto ser chamada de idealista quanto de liberal.

\section{Corrente liberal ou idealista}

O pensamento liberal sobre as relações internacionais foi duramente criticado pelos realistas no pós-Primeira Guerra Mundial, que o acusaram de idealista por fundamentar suas análises em utopias e idéias normativas sobre como deveria ser organizada a vida política, desconsiderando a realidade e as evidências históricas.

No entanto, como bem salienta Martin Griffiths (2004), não há no pensamento liberal internacionalista convicção alguma a respeito da existência de uma utópica harmonia de interesses entre os Estados, passível de ser acionada em âmbito internacional. Segundo o autor, o que é característico desse pensamento é a compreensão de que as ações humanas não são caudatárias dos fatos, como acontece no pensamento realista, mas decorrem da opinião que os homens têm sobre os fatos. Desse modo, entende-se a importância atribuída pelos liberais às idéias e à educação. Pela difusão de idéias constru- 
tivas que demonstrem a incompatibilidade entre a prosperidade material e a guerra e, portanto, a irracionalidade da guerra, seria possível condicionar as ações humanas de modo a fomentar a paz.

Essa confiança depositada na força das idéias é que teria feito Norman Angel, no início do século XX, dedicar-se a escrever sobre as relações internacionais no afã de evitar a guerra, repudiando a sabedoria convencional, responsável, segundo ele, pelo apoio popular a políticas contrárias a seus interesses (Griffiths, 2004, p. 85).

Outro aspecto distintivo do pensamento liberal é a convicção de que a lei que assegura a ordem interna aos Estados pode ser instaurada entre eles, regulando suas relações, apesar das imperfeições previsíveis. A possibilidade de sucesso dessa estratégia decorre, segundo o pensamento liberal, do aumento da interdependência internacional, já vislumbrada por Norman Angel. Num contexto altamente interdependente e próspero, o recurso à guerra seria irracional na medida em que não haveria ganhadores absolutos e as possibilidades de ganhos relativos seriam insuficientemente tentadoras face à certeza das perdas.

Esse pensamento teve grande repercussão no primeiro pós Guerra, tanto que, em 1919, foi criada a Liga das Nações com o intuito de evitar um novo conflito de grandes proporções. A aliança demonstrou seus limites ao não conseguir evitar a Segunda Guerra Mundial, abrindo espaço para uma interpretação radicalmente oposta das relações internacionais, filiada ao realismo político, que dominou as análises das relações internacionais no período entre 1930 e 1960.

Nos últimos anos do século XX, o fim do bloco soviético e os fenômenos da globalização voltam a dar alento a interpretações liberais da realidade internacional. Multiplicam-se, desde então, os estudos que, fundamentados na constatação da crescente interdependência internacional, apostam em desfechos negociados e na viabilidade de uma ordem internacional pacífica. Essa onda de otimismo é contrabalançada pelos atentados terroristas de 11 de setembro de 2001 nos Estados Unidos e por seus desdobramentos, os quais têm reintroduzido as análises de inspiração realista. 


\section{Corrente realista}

Hegemônicos entre 1930 e 1960 e em forte oposição aos liberais, os pensadores realistas tomam os fatos que marcaram a história da humanidade, essencialmente belicosos, como referência para as análises de relações internacionais e criticam os liberais por realizarem o que seria, para eles, prospecções utópicas sobre sociedades ideais.

Os princípios do realismo, enunciados por Morgenthau, afirmam que existem leis objetivas, decorrentes da natureza humana, que governam a política e a sociedade. Tais leis são, portanto, imutáveis, insuscetíveis a preferências humanas. $\mathrm{O}$ realismo se propõe a compreender tais leis e a elaborar uma teoria racional que as reflita, buscando, através da razão, dar sentido aos fatos, distinguindo o que é verdade e o que é mera opinião ou aspiração.

Em termos metodológicos, de acordo com o realismo político, a teoria resulta da observação de recorrências históricas e de suas circunstâncias. Ou seja, o sentido dos fatos internacionais decorre dessa racionalidade. Esse procedimento metodológico assegura, segundo Morgenthau, a observância dos fatos tais como eles são e não como se desejaria que fossem, atendendo a premissa realista de invocar o precedente histórico, em vez de princípios abstratos.

Da perspectiva realista, é impossível atingir o bem absoluto dadas as imperfeições do mundo decorrentes de aspectos próprios da natureza humana. Assim, considerando as imperfeições do mundo, o realismo busca a realização do mal menor ou do bem possível. A contenção da guerra deveria ocorrer não pela sua negação, mas pela busca dos meios de coibi-la uma vez que:

(sendo o mundo de) interesses opostos e de conflitos entre estes, não podem nunca os princípios morais ser inteiramente realizados, mas devem, o mais possível, ser aproximados através do equilíbrio sempre provisório dos interesses e da solução sempre precária dos conflitos (Morgenthau, 1990, p. 131).

Essa leitura da realidade internacional balizou a corrida armamentista durante a Guerra Fria e permanece sendo o substrato teórico de importantes análises das relações internacionais contemporâneas. Segundo a visão determinista dos realistas, os Estados entretêm uma relação de competição constante sem margens para qualquer ação transformadora fundamentada na projeção da vontade humana. 


\section{Transformações mundiais e crise dos postulados realistas}

Os postulados realistas relativos à primazia do Estado, à divisão entre política interna e internacional, entraram em crise nos últimos anos do século $\mathrm{XX}$, quando a crescente interdependência internacional introduziu no cenário, até há pouco dominado pelas potências estatais, novos atores e novas problemáticas que subvertem a ordem anterior e os postulados que balizavam a compreensão da mesma.

$\mathrm{Na}$ ordem atual, as ações dos atores civis e privados passam a ser quase tão determinantes quanto a ação pública dos Estados, embora tais forças atuem em diferentes esferas. Nesse sentido, convém salientar que o âmbito internacional é relacional e não geográfico e que, até muito recentemente, as únicas entidades que reuniam as condições materiais para se relacionarem nesse plano eram quase exclusivamente os Estados, o que tem mudado significativamente nas últimas décadas. Por obra das transformações daí decorrentes, importantes segmentos sociais têm reunido condições suficientes para existirem mundialmente, contribuindo para proscrever a correspondência territorial entre Estado e sociedade.

Pelas razões acima aventadas, a segmentação da política em esferas interna e externa, como detentoras de lógicas diferentes, tem sido superada. Os âmbitos doméstico e internacional encontram-se emaranhados por conta da acelerada diversificação e expansão das atividades econômico-comerciais, financeiras, sócio-culturais e também políticas. A multiplicação de tratados e a consolidação dos chamados regimes internacionais (meio ambiente, comércio etc.) têm introduzido dispositivos regulatórios que tornam o âmbito internacional tão ou quase tão civilizado quanto o meio político interno. Este, ao contrário, tem dado, em muitos casos, claros sinais de incapacidade para assegurar a ordem e a lei que seria, do ponto de vista da teoria do estado de natureza, seu traço característico. A violência nas suas mais variadas formas e as guerras étnicas são exemplos contundentes de que o pacto social tem deixado amplos segmentos a descoberto da proteção estatal. Portanto, os cortes verticais que permitiriam conceber lógicas políticas internas e externas distintas desapareceram, e essas realidades embaralham-se inviabilizando o discernimento entre ordens políticas diferentes. 
Finalmente, os recursos de poder e os meios para ter acesso a eles mudaram significativamente devido aos avanços tecnológicos e ao aumento da interdependência. Nesse contexto, a guerra tem sido vista como um desfecho menos provável, embora possível. Transita-se da ordem estatocêntrica, vigente nos últimos séculos, para uma ordem multifacetada, que recoloca a necessidade de pactos políticos mais amplos. O mundo tornou-se mais complexo e, para entendê-lo, faz-se necessário discernir as lógicas próprias das diferentes dimensões relacionais e as formas como tais dimensões interagem.

Esses desafios têm favorecido a proliferação de estudos no âmbito das Ciências Sociais, em parte, provenientes, como era de se esperar, do âmbito tradicional de estudos internacionais, particularmente próximo da Ciência Política, mas, também, da Sociologia e da Antropologia. É interessante observar que alguns desses estudos confluem significativamente para um campo comum de observação e desenvolvem análises muito complementares. Estudiosos das relações internacionais e da globalização têm desenvolvido conceitos a partir de cortes analíticos transversais no afã de captar a complexidade das relações internacionais atuais. É o caso, por exemplo, do conceito desenvolvido por Boaventura de Sousa Santos de constelações de práticas coletivas (Santos, 2002, p. 56-60). Boaventura denomina as relações de práticas coletivas. Para o autor, três tipos de constelações dão conta das práticas presentes no, por ele denominado, Sistema Mundial em Transição. São elas, a constelação das práticas interestatais que correspondem ao papel dos Estados no sistema mundial moderno; a constelação das práticas capitalistas globais que dizem respeito às práticas dos agentes econômicos com alcance planetário e a constelação das práticas sociais e culturais transnacionais. Estas, segundo o autor, referem-se aos fluxos de pessoas, culturas, informação e comunicação que transcendem fronteiras. Cada constelação é dotada de um conjunto de instituições, uma forma de direito, um conflito estrutural e um critério de hierarquização e todas se interpenetram, gerando o que Boaventura de Sousa Santos denomina de transconflitualidade, ou seja, propiciando a assimilação de um tipo de conflito a outro e fazendo com que se vivencie um conflito como se fosse de outra ordem. Com isso, o autor primeiramente identifica e ordena as relações internacionais (sem assim denominá-las) em dimensões intelectualmente apreensíveis, tomando como critério o tipo de ator envolvido - Estado, agentes econômicos, pessoas. Em seguida, Boaventura de Sousa Santos ressalta as relações entre tais dimensões de modo a evidenciar a complexidade das mesmas. 
Ao identificar lógicas relacionais diferentes e conectadas sob os fenômenos internacionais, Boaventura de Sousa Santos desenvolve conceitos de uma teoria sistêmica das relações internacionais que, apropriadamente, desconhece a distinção entre política interna e externa e busca discernir, transversalmente, as clivagens válidas para o mundo contemporâneo.

A complementaridade entre as contribuições das Teorias Gerais e da de Boaventura Sousa Santos reside no fato de que as primeiras se referem à natureza das relações políticas, enquanto esta última busca discernir a provável estrutura do Sistema Mundial em Transformação.

\section{Considerações finais}

A questão é saber qual a natureza das relações políticas na estrutura do sistema mundial que se delineia no início do século XXI. A complexidade e interdependência do mundo contemporâneo estaria proscrevendo as formas mais brutais e excludentes de relações políticas em benefício de formas consensuadas, ou, ao contrário, a transformação do sistema mundial não estaria produzindo efeitos significativos sobre as formas mais elementares de fazer política? Ou seja, que teoria produziria mais sentido no complexo mundo contemporâneo?

Argumentos tanto de uma quanto de outra teoria encontram ressonância nos acontecimentos atuais. Se observarmos o grau de regulação das relações internacionais e de conexão global entre interesses ou pessoas, somos levados a considerar uma certa comprovação das teses liberais ou idealistas a respeito da possibilidade de a humanidade construir um futuro melhor. Pelo menos em termos materiais, essas condições estão dadas. Por outro lado, persistem graves sinais de barbárie, não restritos a sociedades brutalizadas pela pobreza que reforçam os argumentos a respeito de uma suposta natureza humana perversa, passível de ser contida apenas pela força. Uma e outra natureza de fenômenos reeditam constantemente a necessidade de encontrarmos referenciais que dêem sentido às ações humanas. No que diz respeito a análises científicas, o que é imprescindível saber é que a opção por uma ou outra abordagem não consiste em mera preferência do analista, mas resulta de uma análise contextual em que, muitas vezes, pode-se lançar mão de um sistema conceitual para lançar luz sobre um conjunto de fenômenos sem que isso 
implique necessariamente adesão irrevogável ao mesmo. Ou seja, o analista deve, conhecendo as várias teorias e a história, saber produzir sentido aos fenômenos decorrentes da ação humana com base em diferentes referenciais. $\mathrm{O}$ analista pode, ainda, projetar cenários e sugerir desfechos com base em diferentes concepções teóricas; não pode jamais aderir a uma delas esquecendo que as teorias sociais são sistemas conceituais historicamente desenvolvidos para interpretar o mundo e, como tais, devem servir ao analista.

\section{Referências}

ARON, Raymond. O que é uma teoria das relações internacionais. In: BRAILLARD, Philippe. Teorias das Relações Internacionais. Lisboa: Fundação Calouste Gulbenkian, 1990, p. 148-152.

BRAILlARD, Philippe. Teorias das Relações Internacionais. Lisboa: Fundação Calouste Gulbenkian, 1990.

GRIFFITHS, Martin. 50 grandes estrategistas das Relações Internacionais. São Paulo: Contexto, 2004.

MERLE, Marcel. Sociologie des Relations Internationales. Paris: Dalloz, 1982.

MORGENTHAU, Hans. Uma teoria realista da política internacional. In: BRAILLARD, Philippe. Teorias das Relações Internacionais. Lisboa: Fundação Calouste Gulbenkian, 1990, p. 131-147.

SANTOS, Boaventura de Sousa (org.). A globalização e as Ciências Sociais. São Paulo: Cortez Editora, 2002.

Recebido em $1^{\circ}$ de fevereiro de 2005 e aprovado em 20 de julho de 2005 